given potential is increased. My last three determinations give an increase of $0.30 \pm 0.50$ per cent, $0.70 \pm 0.31$ per cent, and $0.85 \pm 0.59$ per cent, the mean of which is 0.62 per cent. If we make the assumption that this increase is due to there being a period of induction before the electrons start to come off, its duration works out at $5 \times 10^{-10}$ second.

At the highest speed of rotation there is a slight vertical oscillation of the image which puts a limit to the accuracy of the determination, owing to its shifting the light on to a different part of the cathode.

Details of the experiment will be published later.

University, R. A. Houstoun.

Glasgow.

Nov. 27.

${ }^{2}$ Ann. Phys., 41, 124 (1913).

\section{Primary Oxide Film on Iron}

DURING the course of an electron diffraction study of oxide films formed on iron, I have found it rather difficult to obtain surfaces the initial diffraction pattern of which can be attributed to iron alone. In particular, if the surface of a piece of clean Armco or electrolytic iron is abraided by rubbing it lightly over dry 0000 emery paper, the resulting pattern consists of the usual rings of $\alpha$-iron plus two diffuse rings or bands the mean radii of which correspond to spacings of $2 \cdot 6 \mathrm{~A}$. and $\mathrm{I} \cdot 5 \mathrm{~A}$.

The belief that these rings might be due to a thin film of oxide $\left(\mathrm{Fe}_{3} \mathrm{O}_{4}\right)$ has been confirmed by a series of experiments with films of electrolytic iron evaporated and condensed in vacuo on glass, iron, platinum and quartz surfaces. The evaporation was carried out in the diffraction camera with the receiving surface mounted in the sample holder. Reflection pictures taken immediately after evaporation yielded only iron rings. If, however, the sample is exposed to dry air at room temperature and atmospheric pressure for a brief interval, the resulting diffraction pattern is markedly different. The iron rings are considerably fainter, while two diffuse bands appear in the same positions as found on the abraided iron. In some of the pictures other fainter rings appear which, together with the bands, are in good agreement with the pattern to be expected from a thin film of $\mathrm{Fe}_{3} \mathrm{O}_{4}$ overlying the iron.

Traces of oxide on evaporated films have been found on pictures taken after brief exposure to air pressures not exceeding $10^{-3} \mathrm{~mm}$. of mercury. Exposures to atmospheric air longer than four minutes produce very little change in the pattern. Heating the specimens in air for 3-7 min. at temperatures of $150^{\circ}-200^{\circ} \mathrm{C}$. is sufficient to cause the disappearance of the iron rings and greatly to strengthen those due to the oxide.

The possibility that a definite orientation relation. ship exists between the iron and the oxide lattices has been tested by forming thick evaporated films on various surfaces under conditions which yield a high degree of preferred orientation of the individual iron crystals. Such a film all the iron crystals of which have their [111] directions mutually parallel (within $5^{\circ}$ ) exhibits an equally high degree of preferred orientation of the $\mathrm{Fe}_{3} \mathrm{O}_{4}$ film after brief exposure to air. The observed orientation relationship is one in which a $[01 \sqrt{ } 2]$ direction of the cubic oxide crystals is parallel to the [111] direction of the iron. This parallelism does not, of course, determine the complete space orientation relationship between the two lattices. It must be pointed out, however, that the observed orientation is exactly satisfied if the $\mathrm{Fe}_{3} \mathrm{O}_{4}$ cube planes (100) lie parallel to iron cube planes, and the [110] directions in the (100) planes of the oxide are parallel to the [100] directions in the (100) planes of the iron.

Mehl, McCandless and Rhines ${ }^{1}$ have found the same orientation relationship existing between " $\mathrm{FeO}$ " grown at high temperature on single iron crystals. More recently, Mehl and McCandless ${ }^{2}$ have reported that " $\mathrm{FeO}$ " grown by reduction on a single magnetite crystal has the same orientation as the underlying $\mathrm{Fe}_{3} \mathrm{O}_{4}$. In the light of these results, the present experiments can be interpreted by saying that the primary oxide film on iron consists of $\mathrm{Fe}_{3} \mathrm{O}_{4}$ oriented as if " $\mathrm{FeO}$ " were formed first and then oxidized to $\mathrm{Fe}_{3} \mathrm{O}_{4}$. Such is probably not the actual process, because there is no evidence of " $\mathrm{FeO}$ " in the diffraction patterns and furthermore it is unstable below about $575^{\circ} \mathrm{C}$. As has been pointed out by Mehl and McCandless, there is a striking similarity between the positions of the $\mathrm{Fe}$ atoms in the iron lattice and their positions in the "FeO" lattice, and this similarity can be traced through to the $\mathrm{Fe}_{3} \mathrm{O}_{4}$ lattice when it is oriented as described above.

Electron diffraction pictures of $\mathrm{Fe}_{2} \mathrm{O}_{3}$ films grown on highly oriented $\mathrm{Fe}_{3} \mathrm{O}_{4}$ films by heating at $200^{\circ} \mathrm{C}$. in air show no trace of orientation. Continuous rings of the randomly orientated $\mathrm{Fe}_{2} \mathrm{O}_{3}$ crystals appear superimposed on a fading but still well. oriented $\mathrm{Fe}_{3} \mathrm{O}_{4}$ pattern. Long after the $\mathrm{Fe}_{3} \mathrm{O}_{4}$ pattern has disappeared, the $\mathrm{Fe}_{2} \mathrm{O}_{3}$ rings begin to show evidence of a preferred orientation which seems to be independent of the nature and degree of orientation in the underlying layers. Battelle Memorial Institute,
Columbus, Ohio. H. R, Nelson. Nov. 11.

${ }^{1}$ Nature, 134, 1009 (Dec. 29, 1934).

${ }^{2}$ NAture, 137, 702 (April 25, 1936).

\section{Distortion and Yield Point of Molybdenum}

IN a recent communication ${ }^{1}$, Dr. E. W. Fell refers to a letter from us $^{2}$ and comments on the yield point of molybdenum wires after a certain heat-treatment in hydrogen followed by nitrogen, as shown in Fig. 1 (No. 2) of our letter. He points out that in Fig. I (No. 1), which shows the load-extension curve for wires treated in hydrogen only, no such yield point is present, and attributes the difference in the shape of the two curves (that is, No. 1 and No. 2 in our letter) partly to the different heat-treatment affecting the crystal size of the two samples.

While admitting that, in general, the crystal size may have an influence on the yield of the wire, we must point out that, in the particular case dealt with, the crystal sizes of the two samples were exactly identical. Notably the sample No. 2 was pretreated in hydrogen at $1,400^{\circ} \mathrm{C}$. for $2 \mathrm{~min}$., and during the second treatment at $1,300^{\circ} \mathrm{C}$., which was done for 20 sec. in nitrogen, no further change in the crystal structure occurred at all. Thus it is quite clear that the remarkable yield shown is entirely due to the presence of nitrogen sorbed during nitriding at the second treatment.

Incidentally, this can also be demonstrated very convincingly by the following two methods. If 